\title{
A serendipitous finding in face recognition
}

\author{
RICHARD P. HONECK \\ University of Cincinnati, Cincinnati, Ohio
}

\begin{abstract}
During learning, an experimental group heard verbal descriptions of criminal or noncriminal activities of persons whose faces were displayed. A control group saw the faces without the descriptions. An immediate recognition test indicated that the experimental group's performance on new faces was superior to that under all conditions except those for which no crime was described. Apparently a context/contrast effect occurred such that experimental subjects responded as if they knew that new faces had not previously been accompanied by descriptions of crimes. Emotionality and severity of crime dimensions of the descriptions did not correlate with recognition.
\end{abstract}

Do verbal descriptions of faces affect later recognition of the faces? Does the importance/emotionality of the face description affect recognition?

The answer to the first question is mainly negative. Goldstein and Chance (1981) concluded that "the availability or use of verbal codes has little or no effect on face recognition"' (p. 101). Their conclusion was based on findings that (1) the number of verbal responses elicited by face and nonface (inkblot, snowcrystal) stimuli does not correlate with recognition; (2) subjects instructed to describe faces, versus to look-to-remember them, do recognize the faces slightly better a week later, but rarely recall their descriptions; (3) accuracy of descriptions of faces in memory does not necessarily predict face recognition; and (4) verbal tasks interfere less with face recognition than do visual tasks. Yarmey (1979) maintained that verbal labels can facilitate the recognition of visual stimuli, but that these stimuli are almost always less meaningful than faces. This generalization applies to schematic faces also; that is, hard-to-describe faces are recognized better if they are first labeled than if they are not. Indeed, labeling of meaningful stimuli may degrade recognition (Bahrick \& Boucher, 1968).

The evidence regarding the role of importance/ emotionality of descriptors in recognition is less clear. There seems to be no direct evidence that pertains to the question. Indirect evidence from levels-of-processing studies indicate that making "verbal inferences about personal characteristics of pictured persons rather than assessing the physical characteristics of the faces shown is a useful mnemonic strategy" (Goldstein \& Chance, 1981, p. 97). Since the personal characteristics have often involved dimensions such as beauty, pleasantness, and heaviness, importance/emotionality may have played a role. Goldstein and Chance (1981) argue that more "beautiful" faces, for example, may be more unique, and that unique codes are more likely to be aroused during a recognition test. By contrast viewer stress and anxiety, both

The author's mailing address is: Psychology Department, ML 376, University of Cincinnati, Cincinnati, OH 45221. social-contextual traits and personal traits, tend to degrade recognition (Deffenbacher \& Horney, 1981). However, recognition is improved if people have foreknowledge about the seriousness of a criminal act, where seriousness is measured by the monetary value of stolen goods (Leippe, Wells, \& Ostrom, 1978).

In the present study, the experimental group heard either crime or noncrime descriptions, varying in emotionality, immediately before seeing faces. The control group saw the faces without the descriptions. If descriptions impair learning, then the experimental group should show poorer performance, largely in the form of "misses," on a recognition test. The crime/noncrime dimension was added to determine whether it would differentially affect recognition.

\section{METHOD}

\section{Subjects}

The subjects were 46 students from introductory psychology courses at the University of Cincinnati. They received points worth course credit for participating.

\section{Materials}

Thirty-two pictures and 16 phrases were used.

Pictures. The pictures were selected from the Congressional Pictorial Directory (1983-84). Only pictures of men from outside Ohio who were unfamiliar in terms of media exposure were selected. The pictures were copied from the directory, and the copies were taped onto white paper so that they could be shown by an opaque projector. The pictures were black-and-white frontal shots of white males approximately 35-50 years old. Each picture showed a body from about 5-6 in. below the chin and up. All of the men wore sports coats that appeared dark on the copies and relatively nondescript ties that were visible approximately from the knot up, and all were smiling to a greater or lesser degree. Leafing through the pictures, one is struck by their homogeneity, an impression that is partly due to the copying process, since it degraded the clarity of the pictures. This degradation can be considered beneficial, however, since it stacks the cards against any independent variable's having reliable effects on recognition unless its effects are potent. Finally, 16 of the faces were randomly selected to be used during the learning phase. The other 16 served as new items during the recognition test.

Verbal descriptions. There were eight phrase-length descriptions of crimes and eight phrase-length descriptions of noncriminal activities. Both types of descriptions were constructed so that they would vary in the emotionality they evoked, from low to high emotion. The experimenter tape-recorded all of the descriptions in an emotionally neutral manner. 
The crime descriptions were as follows: stole a pair of gloves from a store, trashed some empty apartments, wrote a bad $\$ 500$ check, knocked someone down and took their radio, beat up a stranger and left him in the street, embezzled a million dollars from a bank, kidnapped a young child, murdered five people.

The noncrime descriptions were as follows: listened to a concert on the radio, took a pleasant two-week vacation, went for a walk in the park, went fishing on a quiet lake, had an angry argument with his boss, collided with another car and got whiplash, broke up with his longtime girlfriend, lost his brother to cancer.

\section{Design}

Twenty-six subjects were randomly assigned to the experimental group and 20 to the control group. During the learning phase, the experimental group saw each of 16 pictures immediately after hearing a verbal description. The control group saw the pictures without hearing any descriptions. Both groups then completed a recognition task that included the 16 old pictures and 16 new ones. The experimental group then ranked the crime descriptions for severity and then rated all 16 verbal descriptions for their emotionality.

\section{Procedure}

The subjects were tested in groups in a small quiet room. They sat facing a wall 8-15 ft away. Both groups were first instructed that they were going to see some pictures projected on a wall and that they should inspect them carefully. The experimental group was further instructed that they would hear a short tape-recorded description of the person in each picture.

During acquisition, there were 16 trials. On each trial, the prerecorded word "next" occurred. For the control group, a picture was then presented for $10 \mathrm{sec}$. All pictures were presented via an opaque overhead projector. For the experimental group, the prerecorded word "next" was followed by a 2 -sec pause, a verbal description, an immediate repetition of the description, and a 10-sec presentation of a picture. Two different orders of pictures were balanced across the subjects in each group.

After the last acquisition trial, all subjects were told that a recognition test involving the old and an equal number of new pictures would be given in a few minutes. They were further instructed that the pictures would be presented in a random order for $12 \mathrm{sec}$ each. They were then given a single piece of paper, called "Recognition Test," that contained the numbers 1-32 and the answers "yes" and "no" alongside each number. The paper instructed them to circle "yes" if they had seen the picture before and "no" if they had not. The experimenter verbally repeated this instruction and cautioned the subjects to respond on every trial.

The experimenter then went to an adjoining room and placed the old and new pictures in their proper order for presentation. This took about $4 \mathrm{~min}$. Two different random picture orders were balanced across the subjects in each group.

There were 32 test trials. On each trial, the prerecorded word "next" was presented, then each picture was presented for $12 \mathrm{sec}$. This was adequate time for subjects to inspect each picture and make their responses.

\section{RESULTS}

\section{Recognition Performance}

The experimental group showed an $87.14 \%$ correct response rate. Performance on crime-described pictures $(80.28 \%)$ did not differ significantly from that on noncrime-described pictures $(86.05 \%)$. However, performance on the nondescribed or new pictures $(91.13 \%)$ was superior to that on the crime-described (old) pictures but equal to that on the noncrime-described (old) pictures $[t(25)=2.35, p<.05$, and $t(25)=1.44, p>.05$, respectively].
The control group showed an $80.31 \%$ correct response rate. Performance on old pictures $(78.44 \%)$ did not differ from that on new pictures $(82.19 \%)[t(19)=.19$, $p>$.05]. Additionally, overall control group performance did not differ from that of the experimental group on described pictures $[t(44)=.85, p>.05]$. However, the experimental group's performance on nondescribed (new) pictures was better than that of the control group $[t(44)=2.91, p<.01]$.

The error patterns, or misses and false alarms, did not differ for the two groups. For the experimental group, $66.36 \%$ of their errors were misses; the figure was $55.56 \%$ for the control group $[Z=.74, p>.05]$.

\section{Crime Severity and Emotionality Effects}

Neither variable correlated with recognition performance by the experimental group. Mean rank for crime severity and number of hits on crime-described pictures were uncorrelated $[r(6)=.07, p>.05]$. However, $N$ was only 8 , and the recognition scores were very homogeneous (range 2-8). Similarly, the mean emotionality ratings on the verbal descriptions did not correlate with number of hits on the verbally described pictures $[r(14)=.01, p>.05]$. Again, however, the recognition scores were very homogeneous (range 16-25 correct).

\section{DISCUSSION}

The results were clear but unanticipated. The experimental group recognized new faces better than old crime-described faces, but not better than old noncrime-described faces. The control group's performance on both old and new faces was equal to the experimental group's performance on described faces.

The experimental group's superior performance on new faces appears to be due to a context/contrast effect. That is, when new faces are viewed in the context of old, especially crime-described faces, correct rejection of the former soars above a baseline (control) rate. It is as if the subjects knew that the new pictures were not pictures of people described as having committed a crime. Still, it is not clear whether the context effect is due to having experienced both crime and noncrime descriptions, or only crime descriptions. Thus, although the results are consistent with Goldstein and Chance's (1981) conclusion that verbal codes have little effect on face recognition, the codes may have an indirect, facilitative effect. Also, whether the effect would occur if both described and undescribed faces were presented during learning remains to be seen.

The emotionality and severity of crime variables were ineffective. There may be several reasons for this. First, although descriptions of faces as beautiful, for example, tend to improve their recognition, faces were not described in the present study; rather, the depicted person's activities were described. Second, for this reason, crime/noncrime descriptions of activities may be irrelevant to face recognition. Finally, although Leippe et al. (1978) found that severity of crime (amount of money stolen) correlated with recognition, in the present study crime severity was multidimensional (theft, murder, etc.). Whether this or other methodological differences between the studies produced the varied results is not clear.

\section{REFERENCES}

BAHRICK, H. P., \& BoUCHER, B. (1968). Retention of visual and verbal codes of the same stimuli. Journal of Experimental Psychology, 78, $417-422$. 
Deffenbacher, K. A., \& Horney, J. (1981). Psycholegal aspects of face identification. In G. Davies, H. Ellis, \& J. Shepherd (Eds.), Perceiving and remembering faces (pp. 201-226). New York: Academic Press.

Goldstein, A., \& CHANCE, J. (1981). Laboratory studies of face recognition. In G. Davies, H. Ellis, \& J. Shepherd (Eds.), Perceiving and remembering faces (pp. 81-104). New York: Academic Press.

LeIPPE, M. R., Wells, G. L., \& Ostrom, T. M. (1978). Crime seri- ousness as a determinant of accuracy in eyewitness identification. Journal of Applied Psychology, 63, 345-351.

NineTY-EIGHTH CongRess. (1983-84). Congressional pictorial directory. Washington, DC: Government Printing Office.

YARMEY, A. D. (1979). The psychology of eyewitness testimony. New York: The Free Press.

(Manuscript received for publication April 14, 1986.) 